\title{
Modelling and simulation of a thermoelectric structure with pellets of non-standard geometry and materials
}

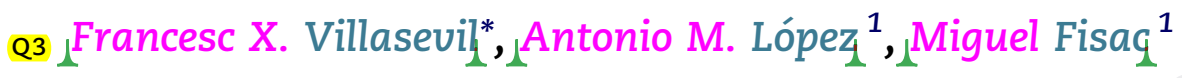 \\ Universitat Politècnica de Catalunya, EPSEVG, Auda. Víctor Balaguer s/n, 08800 Vilanova i la Geltrú, Barcelona, Spain
}

\section{A R T I C L E I N F O}

Article history:

Received 9 May 2012

Received in revised form

15 February 2013

Accepted 16 February 2013

Available online $\mathrm{xxx}$

Keywords:

Peltier

Thermoelectric refrigeration

Finite Element Model

Seebeck

Non-standard materials

\section{A B S T R A C T}

The aim of this paper is to develop and manufacture a thermoelectric structure operating in Peltier mode with non-standard materials, using a Finite Element Model. Thus, both the reliability of the Finite Element Model and the correct development and design of the new thermoelectric structure are ascertained, achieving a dual goal of our research group. This work provides a very good correlation between simulated and experimental results, and corroborates that the material's performance has a decisive influence on the thermoelectric properties of the structure in the temperature range of study considered.

(c) 2013 Elsevier Ltd and IIR. All rights reserved.

\section{Introduction}

Since the discovery of thermoelectric phenomena two centuries ago (Seebeck effect, Peltier effect, and Thomson effect), their application in both heat pump (Peltier effect) and electrical power generation (Seebeck effect) has experienced an important increase during the last 60 years.

Thermoelectric technology is currently spreading across many application areas such as power generation from waste heat (Kajikawa, 2006), thermoelectric systems in the automotive industry (Matsubara and Matsuura, 2006), as well as being applied to space missions (Abelson, 2006) and for cooling electronic components (Semenyuk, 2006).

Therefore, this article describes the development of a thermoelectric module made of non-standard $\mathrm{p}$ - $\mathrm{n}$ semiconductors. These materials are compounds of type $\left(\mathrm{Bi}_{2} \mathrm{Te}_{3}\right)_{1-x-y}\left(\mathrm{Sb}_{2} \mathrm{Te}_{3}\right)_{x}\left(\mathrm{Sb}_{2} \mathrm{Se}_{3}\right)$, and show good thermoelectric properties as n-type and p-type materials within a

\footnotetext{
* Corresponding author. Tel.: +3493 8967728; fax: +34938967700.

E-mail addresses: francisco.javier.villasevil@upc.edu (F.X. Villasevil), lopezm@eel.upc.edu (A.M. López), miguel.fisac@upc.edu (M. Fisac).

${ }^{1}$ Tel.: +34 93 8967728; fax: +34938967700.

0140-7007/\$ - see front matter @ 2013 Elsevier Ltd and IIR. All rights reserved.

http://dx.doi.org/10.1016/j.ijrefrig.2013.02.014
}

Please cite this article in press as: Villasevil, F.X., et al., Modelling and simulation of a thermoelectric structure with pellets of non-standard geometry and materials, International Journal of Refrigeration (2013), http://dx.doi.org/10.1016/ j.ijrefrig.2013.02.014 


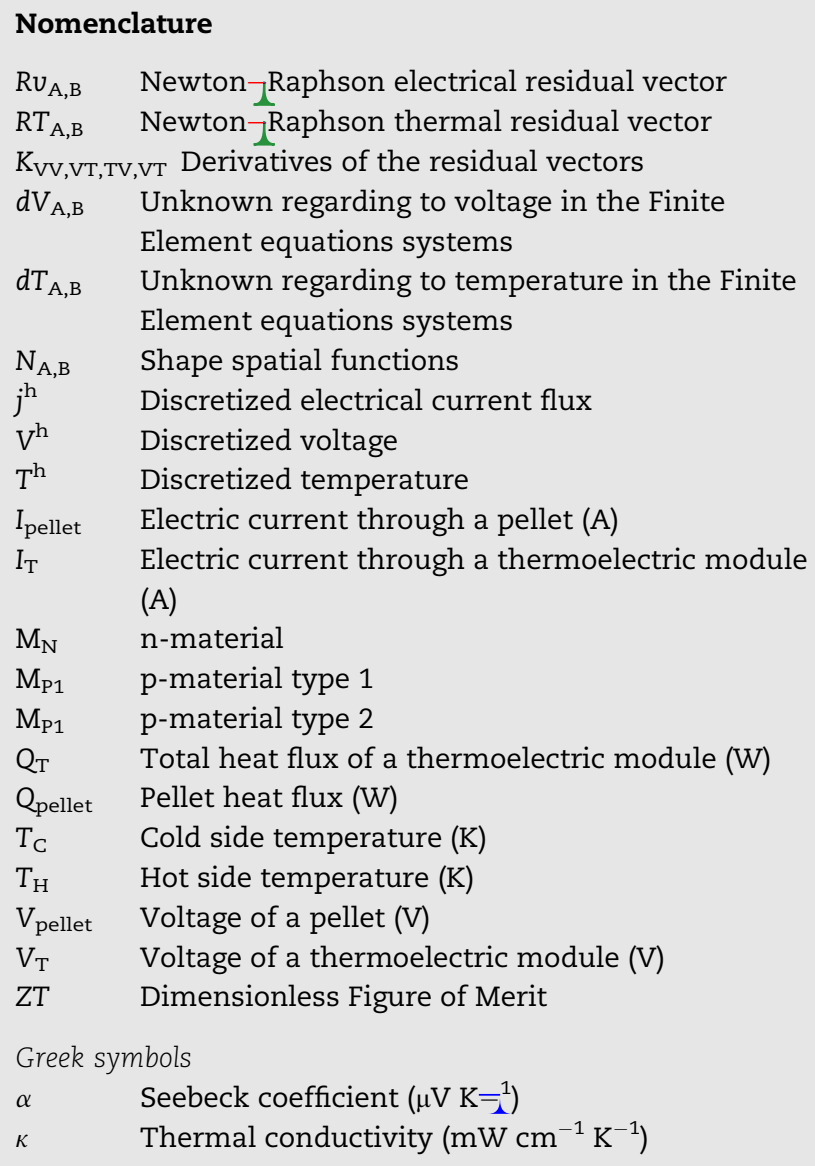

\section{$\sigma$}

$\Gamma$

$\Omega$

$\eta_{\mathrm{V}} \quad$ Set of nodes belong to $\Gamma_{\mathrm{V}}$

$\eta_{\mathrm{T}} \quad$ Set of nodes belong to $\Gamma_{\mathrm{T}}$

$q^{\text {h }} \quad$ Discretized thermal flux

$\alpha^{\mathrm{h}} \quad$ Discretized Seebeck coefficient

$\kappa^{\text {h }} \quad$ Discretized thermal conductivity

$\sigma^{\text {h }} \quad$ Discretized electrical conductivity

Formulas

$\mathrm{Bi}_{2} \mathrm{Te}_{3} \quad$ Bismuth telluride

$\mathrm{SbI}_{3} \quad$ Antimony triiodide

$\mathrm{Sb}_{2} \mathrm{Se}_{3}$ Antimony selenide

$\mathrm{Sb}_{2} \mathrm{Te}_{3}$ Antimony telluride

\section{Subscripts}

A, B Nodes in Finite Element formulation

$\mathrm{T} \quad$ Regarding to temperature or heat transfer

V Regarding to electrical phenomena

method

C Cold side

Ce Ceramics

$\mathrm{Cu}$ Copper

$\mathrm{H} \quad$ Hot side

S Welding

Superscript

h Discretized variable i Iteration number in the Newton ${ }_{\square}$ Raphson

temperature range from $270 \mathrm{~K}$ to $450 \mathrm{~K}$. These $\mathrm{p}-\mathrm{n}$ semiconductors have been obtained through the BridgmanStockbarger technique (Kuznetsov et al., 2002). It should be noted that the module suggested in this paper is intended to perform within a food cooling system and a cigar humidor, due to its low power consumption and its high refrigerating power.

Nowadays, authors such as Cai et al. (2011) have used analytical models to develop thermoelectric structures, obtaining optimal results. Other authors have used numerical methods to simulate the behaviour of thermoelectric modules (Yu and Zhao, 2007). In this paper a discrete model based on Finite Elements was used. This model has been already tested in commercial structures and other internal developments through specific software (Pérez-Aparicio et al., 2007, 2012). The results have been satisfactory, thus validating its utility.

\section{Thermoelectric properties of materials considered}

We have developed, characterized and tested thermoelectric plates with pellets made of materials generated and characterized within the research group. The materials used are the following:

- $\mathrm{M}_{\mathrm{P} 1}$ : p-type material $\left(\mathrm{Bi}_{2} \mathrm{Te}_{3}\right)_{0.3}\left(\mathrm{Sb}_{2} \mathrm{Te}_{3}\right)_{0.67}\left(\mathrm{Sb}_{2} \mathrm{Se}_{3}\right)_{0.03}$ doped with $\left(\mathrm{SbI}_{3}, \mathrm{Te}\right)$ type 1 .

- $\mathrm{M}_{\mathrm{P} 2}$ : p-type material $\left(\mathrm{Bi}_{2} \mathrm{Te}_{3}\right)_{0.3}\left(\mathrm{Sb}_{2} \mathrm{Te}_{3}\right)_{0.67}\left(\mathrm{Sb}_{2} \mathrm{Se}_{3}\right)_{0.03}$ doped with $\left(\mathrm{SbI}_{3}, \mathrm{Te}\right)$ type 2 .

- $\mathrm{M}_{\mathrm{N}}$ : n-type material $\left(\mathrm{Bi}_{2} \mathrm{Te}_{3}\right)_{0.8}\left(\mathrm{Sb}_{2} \mathrm{Te}_{3}\right)_{0.1}\left(\mathrm{Sb}_{2} \mathrm{Se}_{3}\right)_{0.1}$ doped with $\left(\mathrm{SbI}_{3}\right)$.

These materials can form cells of two types: one with $\mathrm{M}_{\mathrm{P} 1}$ and $\mathrm{M}_{\mathrm{N}}$ pairs, and another one with $\mathrm{M}_{\mathrm{P} 2}$ and $\mathrm{M}_{\mathrm{N}}$ pairs. This paper shows the development of a structure with $M_{P 1}$ and $M_{N}$ materials. The thermoelectric properties at room temperature $(300 \mathrm{~K})$ of these materials are shown in Table 1.

\section{Design and simulation model}

The Finite Element Model used allowed us to find a spatial distribution of electric potential and temperature in a volume $\Omega$ contained in a closed surface $\Gamma$, with specific electrical and thermal boundary conditions (Virjoghe et al., 2010). The model is based on second-order differential equations, which are simplified (first-order integral) and discretized for application in the Finite Element theory, thus obtaining a system of non-linear equations which we solved with the Newton ${ }_{\boldsymbol{L}}$ Raphson method (Gavela and Pérez-Aparicio, 1998), as shown below: 
Table 1 - Thermoelectric properties of materials used ( $T=300 \mathrm{~K})$.

\begin{tabular}{lccccc} 
Material & Type & Seebeck coefficient & Electrical conductivity & Thermal conductivity & Figure of Merit ZT \\
\hline $\mathrm{M}_{\mathrm{P} 1}$ & $\mathrm{p}$ & 160 & 1900 & 19.3 & 2.4 \\
$\mathrm{M}_{\mathrm{P} 2}$ & $\mathrm{p}$ & 182 & 1290 & 15.2 & 2.8 \\
$\mathrm{M}_{\mathrm{N}}$ & $\mathrm{n}$ & -176 & 1710 & 19 & 2.8 \\
\hline
\end{tabular}

The $\mathrm{M}_{\mathrm{P} 1}$ sample has a higher carrier concentration compared to the $\mathrm{M}_{\mathrm{P} 2}$ sample. Therefore, $\mathrm{M}_{\mathrm{P} 1}$ has higher electrical and thermal conductivity. Both samples show a thermal conductivity lower than $\mathrm{Bi}_{2} \mathrm{Te}_{3}$ (Ivanova et al., 2002).

$K_{\mathrm{TV}_{\mathrm{AB}}}=-\frac{\partial \mathrm{R}_{\mathrm{T}_{\mathrm{A}}}}{\partial \mathrm{d}_{\mathrm{T}_{\mathrm{B}}}}=\int_{\Omega} \nabla \mathrm{N}_{\mathrm{A}} \frac{\partial q^{h}}{\partial d_{\mathrm{T}_{\mathrm{B}}}} d \Omega-\int_{\Omega} \mathrm{N}_{\mathrm{A}} \frac{\partial j^{h}}{\partial d_{\mathrm{T}_{\mathrm{B}}}} \nabla \mathrm{V}^{\mathrm{h}} \mathrm{d} \Omega \quad \mathrm{A}, \quad B \in \eta-\eta_{\mathrm{V}}$

From Equation (4), the value of the derivatives can be obtained according to the intrinsic characteristics of the semiconductor:

$\frac{\partial j^{h}}{\partial d_{V_{B}}}=-\sigma^{h} \nabla N_{B}$

$\frac{\partial j^{h}}{\partial d_{T_{B}}}=-\alpha^{h} \sigma^{h} \nabla N_{B}-\frac{\partial \alpha^{h}}{\partial T} \sigma^{h} \nabla T^{h} N_{B}-\frac{\partial \sigma^{h}}{\partial T}\left(\nabla V^{h}+\alpha^{h} \nabla T^{h}\right) N_{B}$

$\frac{\partial q^{h}}{\partial d_{V_{B}}}=\alpha^{h} T^{h} \frac{\partial j^{h}}{\partial d_{V_{B}}}$

$\frac{\partial q^{h}}{\partial d_{T_{B}}}=\alpha^{h} T^{h} \frac{\partial j^{h}}{\partial d_{T_{B}}}+\alpha^{h} j^{h} N_{B}-\kappa^{h} \nabla N_{B}+\frac{\partial \alpha^{h}}{\partial T} T^{h} j^{h} N_{B}-\frac{\partial \kappa^{h}}{\partial T} \nabla T^{h} N_{B}$

If $d_{V}$ and $d_{T}$ are vectors containing the unknowns:

$\mathrm{d}_{\mathrm{V}}=\left\{\mathrm{d}_{\mathrm{V}_{\mathrm{B}}}\right\} \quad B \in \eta-\eta_{\mathrm{V}}$

$\mathrm{d}_{\mathrm{T}}=\left\{\mathrm{d}_{\mathrm{T}_{\mathrm{B}}}\right\} \quad \mathrm{B} \in \eta-\eta_{\mathrm{T}}$

Then we can apply the Newton ${ }_{\Lambda}$ Raphson iterative process in order to find the values for $d_{V}$ and $d_{T}$. The process can be described in matrix form as follows, where $i$ is the corresponding iteration:

$\left\{\begin{array}{l}d_{V_{i+1}} \\ d_{T_{i+1}}\end{array}\right\}=\left\{\begin{array}{l}d_{V_{i}} \\ d_{T_{i}}\end{array}\right\}+\left\{\begin{array}{ll}K_{V V} & K_{V T} \\ K_{V T} & K_{T T}\end{array}\right\}_{i}^{-1} \cdot\left\{\begin{array}{l}R_{V} \\ R_{T}\end{array}\right\}_{i}$

In Equations (5)-(8), this three-dimensional model can replace the intrinsic characteristics of the $\mathrm{M}_{\mathrm{P} 1}$ and $\mathrm{M}_{\mathrm{N}}$ semiconductors, used in the formation of $p-n$ pairs. Properties of the remaining elements in the thermoelectric system, such as copper, aluminium oxide, and welding, are considered.

Copper shows values of $\alpha_{\mathrm{Cu}}=1.84 \mu \mathrm{V} \mathrm{K} \mathrm{K}^{-1}$, $\sigma_{\mathrm{Cu}}=5.81 \cdot 10^{7} \Omega^{-1} \mathrm{~m}^{-1}$ and $\kappa_{\mathrm{Cu}}=386 \mathrm{~W} \mathrm{~m}^{-1}$, with electrical and thermal conductivities assumed to be temperatureindependent. In the case of aluminium oxide, with which ceramics is made, we obtain a value of $\kappa_{\mathrm{Ce}}=35.3 \mathrm{~W} \mathrm{~m}^{-1}$, also assumed to be temperature-independent. Finally, in the joint welding $(\mathrm{SnPb})$ between the thermoelements, we obtain $\sigma_{\mathrm{S}}=17 \cdot 10^{4} \Omega^{-1} \mathrm{~m}^{-1}$ and $\kappa_{\mathrm{S}}=48 \mathrm{~W} \mathrm{~m}^{-1}$, also with constant properties. The values of the Seebeck coefficients of $\mathrm{p}-\mathrm{n}$ materials and the remaining elements of the thermoelectric system have been obtained experimentally by performing a Seebeck Scanning Microprobe, ${ }_{2}$ as detailed in Platzek et al. (2005).

In the simulation, it is assumed that all pairs of thermocouples behave the same way. This depends mainly on the temperature distribution between the two faces of the pellet (Antonova and Looman, 2005). If the temperature on the faces is homogeneous, all pairs of thermocouples work under the same conditions. Therefore, including only one pair of thermocouples is enough, considering the top as the cold face, and the bottom as the hot face. Electric current enters the model through the bottom left side of the copper conductor, and leaves it through the bottom right side-(Fig. 1).

It was decided to build a board of 49 pairs of thermocouples, with pellets made of the materials considered, $\mathrm{M}_{\mathrm{P} 1}$ and $\mathrm{M}_{\mathrm{N}}$. These pellets have a size of $3 \mathrm{~mm} \times 3 \mathrm{~mm} \times 3 \mathrm{~mm}$. The total sizing of the thermoelectric system with distribution of the 49 pairs ( 98 pellets) is shown in Figs. 2 and 3.

\subsection{Boundary conditions}

The boundary conditions have been established as follows:

-It is assumed that the entire contour is open. Therefore, the contour is not thermally insulated and the ceramic faces (upper and lower) are considered at homogeneous temperatures $T_{h}$ and $T_{c}$. Moreover, there is convection in the thermocouples. After the transient period $T_{h}$ and $T_{c}$ tend to be constant.

-It is assumed that the entire contour is electrically insulated, except for the ends of the copper conductors through which electric current enters and leaves.

The model supports three input parameters: the electric current through the module, the temperature of the hot face, and the temperature of the cold face. The model calculates the voltage and temperature in domain points, obtaining 


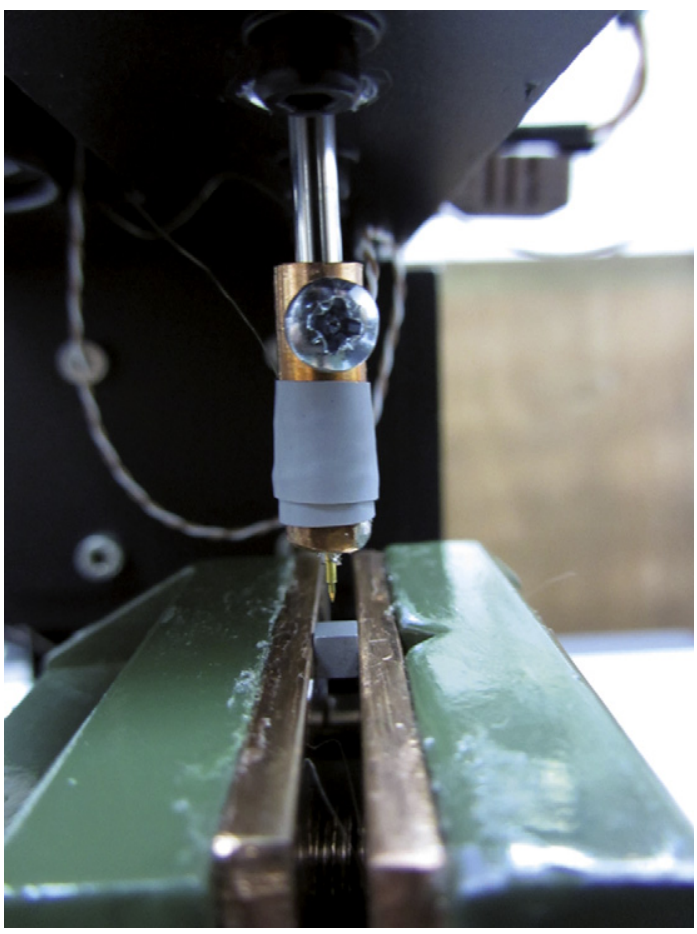

Fig. 1 - Scanning Seebeck microprobe carried out on a $\mathbf{M}_{\mathrm{P} 1}$ pellet.

both current and heat flux. From this spatial distribution, we can also obtain important operating parameters of the pellets, such as the voltage applied to the couple, the heat extracted from the cold face and the heat dissipated on the hot face.

This last parameter is not independent of the rest, since the heat dissipated on the hot face must equal the heat absorbed by the cold face plus the electrical power consumed. However, the heat dissipated on the hot face obtained by the

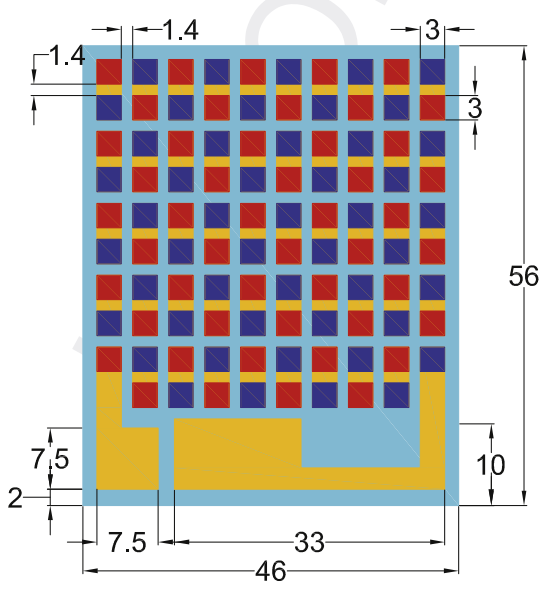

model confirms that everything works properly. In order to relate the operating conditions of the pellet to the parameters of the model, we will take the considerations described below.

\subsection{Input parameters}

Electric current. All thermoelectric couples are connected in series and supplied by constant voltage, which means that the total electrical power consumed by the cell flows through the couples. This model includes 49 couples, so the electric current applied to the model will be the same that flows through a pellet, that is $I_{\mathrm{T}}=I_{\text {couple }}=I_{\text {pellet }}$.

\subsection{Output parameters}

Voltage. The total voltage applied to the thermoelectric system is the sum of all couples, that is, $V_{T}=98 \times V_{\text {pellet }}$. To maintain the value of the electric current $I_{\text {pellet }}$ it is necessary to supply the system with a voltage $\mathrm{V}_{\mathrm{T}}$.

Heat flux. The heat exchanged between the plate and the faces is the amount of heat for every couple, that is, $\mathrm{Q}_{\mathrm{T}}=98 \times \mathrm{Q}_{\text {pellet}}$, assuming no losses in all associated elements (ceramics, welding, etc.).

The results obtained in the simulations, taking into account the complete structure parameters, are described in detail in the following sections.

\section{Structure study operating in Peltier mode}

\subsection{Results obtained in the simulation}

Considering that the thermoelectric structure is working in Peltier mode, the following results were obtained with 250 differential elements in the iteration. In these simulations we can see the theoretical behaviour of the plate, which can then be compared to the measurements carried out on the developed structure. The theoretical development of temperature

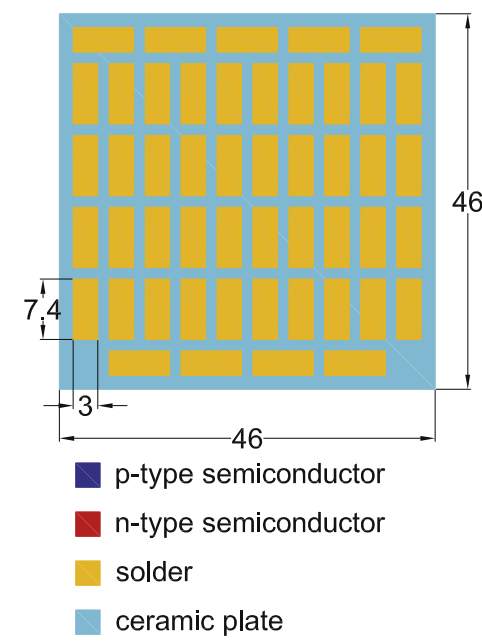

Fig. 2 - Design scheme of the thermoelectric module. 

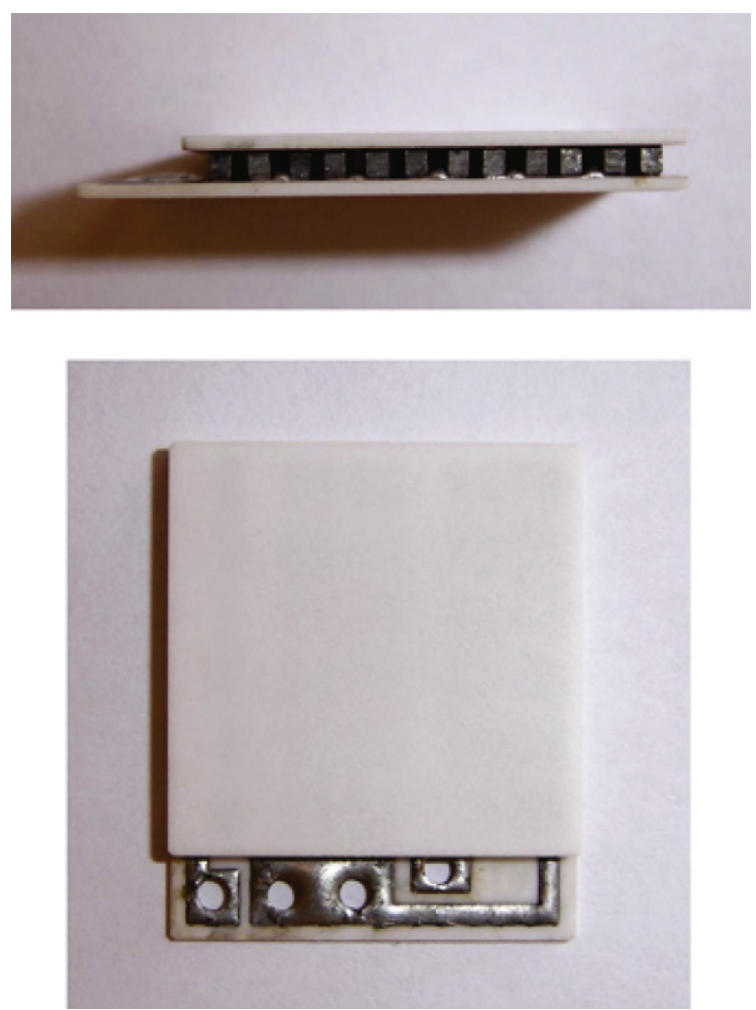

Fig. 3 - Thermal structure developed.

in the time domain for different values of input current (1, A, 1.5 $\mathrm{A}, 2 \mathrm{~A}, 2 . \mathrm{L}_{\mathrm{A}} \mathrm{A}$ and 3A) for $100_{\mathrm{L}} \mathrm{S}$ is shown in Fig. 4.

\subsection{Experimental results}

The measurements on the designed and developed structure were performed with the same values of electrical current (1A,

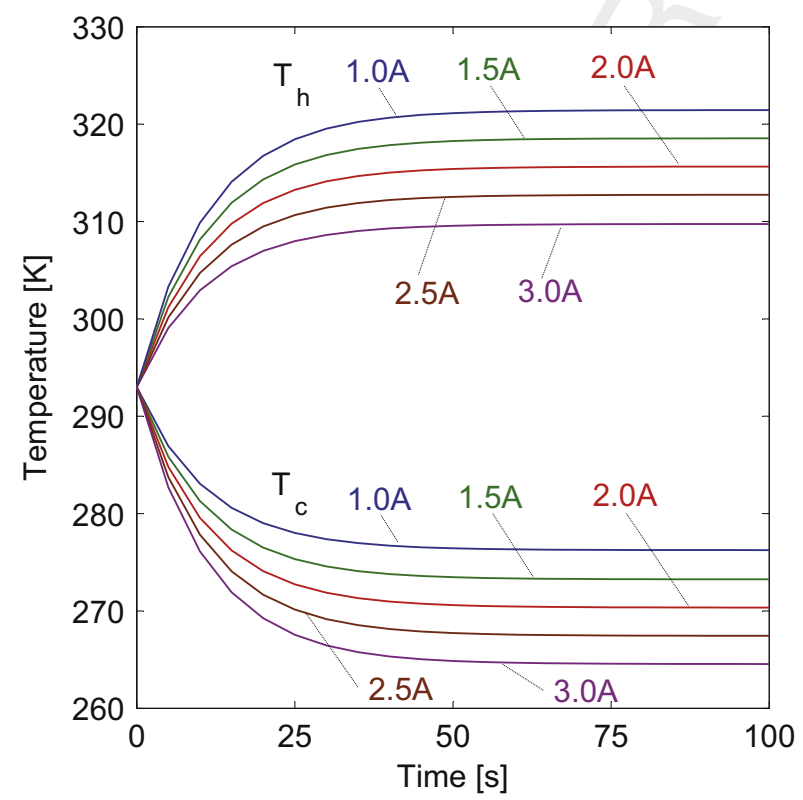

Fig. 4 - Simulation of the temperature evolution on the hot and cold faces for different current values.

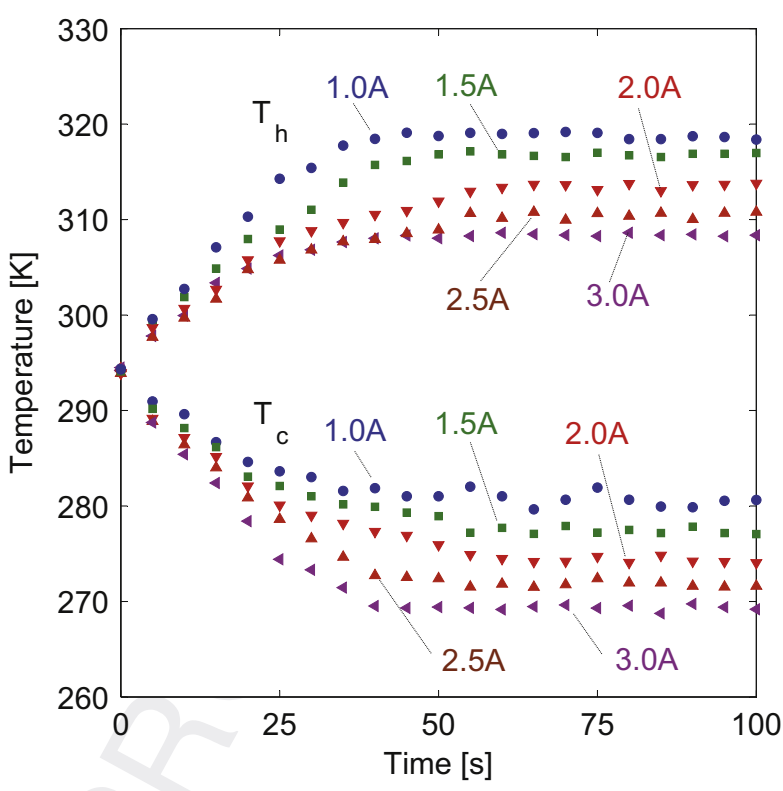

Fig. 5 - Experimental measurements of the temperature evolution on the hot and cold faces for different current values.

1.5A, 2A, 2.5A, and 3A). Temperatures $\mathrm{T}_{\mathrm{H}}$ and $\mathrm{T}_{\mathrm{C}}$ were obtained for each current value, as shown in Fig. 5.

As shown in Figs. 6 and 7, although the simulation response is slightly faster while booting the system than in the experimental module, the difference between the experimental and theoretical results decreases over time. Therefore, the difference is minimal and the model behaves correctly.

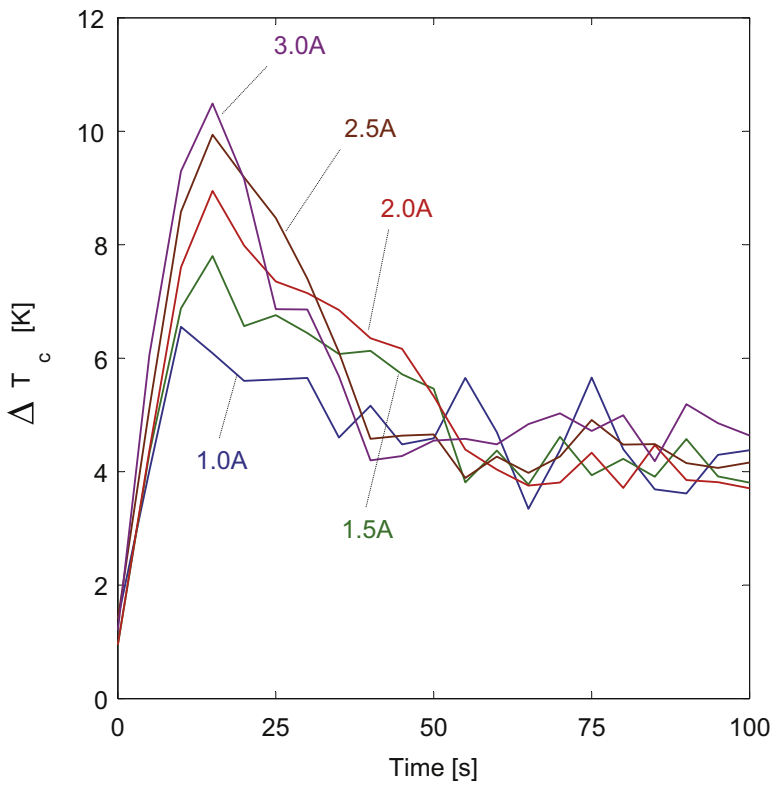

Fig. 6 - Difference between experimental and theoretical values on the cold face for different current values.

Please cite this article in press as: Villasevil, F.X., et al., Modelling and simulation of a thermoelectric structure with pellets of non-standard geometry and materials, International Journal of Refrigeration (2013), http://dx.doi.org/10.1016/ j.ijrefrig.2013.02.014 


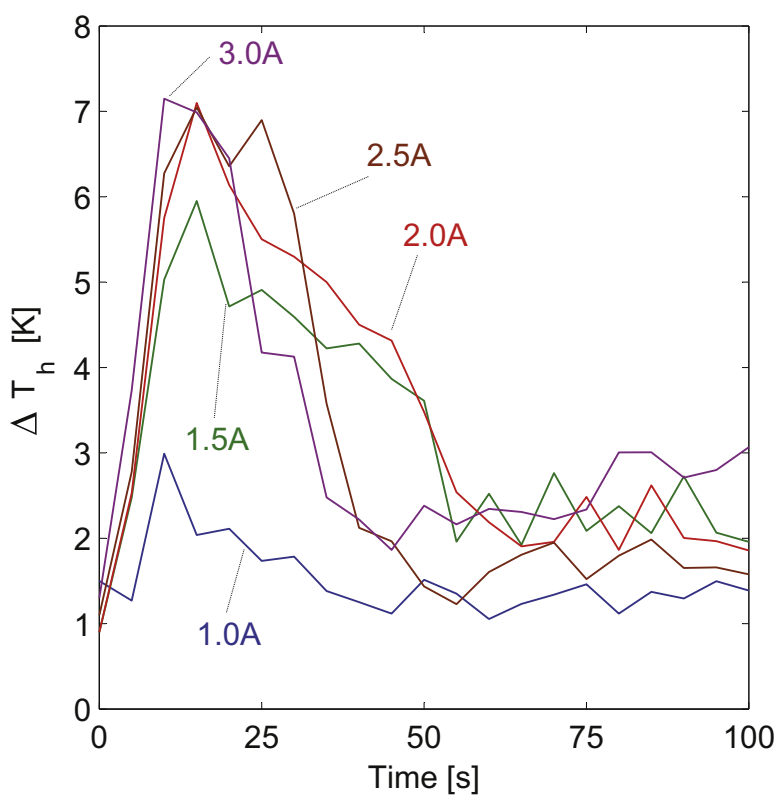

Fig. 7 - Difference between experimental and theoretical values on the hot face for different current values.

\section{Conclusions}

In this paper we have characterized a thermoelectric structure with p-type thermocouples formed by $\left(\mathrm{Bi}_{2} \mathrm{Te}_{3}\right)_{0.3}$ $\left(\mathrm{Sb}_{2} \mathrm{Te}_{3}\right)_{0.67}\left(\mathrm{Sb}_{2} \mathrm{Se}_{3}\right)_{0.03}$ doped with (SbI $\left.{ }_{3} \mathrm{Te}\right)$ type 1, in the temperature range from $270 \mathrm{~K}$ to $450 \mathrm{~K}$. After the different simulations and tests have been executed, we can deduce a direct relationship between the thermoelectric properties of the module and the properties of the constituent material of the pellets. Therefore, we can confirm the expectations of our previous studies, which allowed us to sense the influence of the pellet properties on the behaviour of the thermoelectric module.

Comparisons between simulation results and experimental results show a very good correlation, especially regarding the heat extracted from the cold face. Furthermore, it should be noted that small deviations in temperature are largely due to the not well-known values of the actual conductivity and thickness of the copper junctions of the thermocouple implemented during the development of the module. Moreover, it should be pointed out that deviations obtained by Cai et al. (2011) and Yu and Zhao (2007) with their modules are in the same order of magnitude as those obtained with the model proposed in this paper.

Thus, in addition to characterising the thermoelectric structure, the reliability of the Finite Element Model used has been verified, since the theoretical values obtained are very similar to the experimental results. Furthermore, as discussed above, the influence of thermoelectric materials on the module behaviour in the considered temperature range of study has been confirmed to be decisive.

\section{R E F E R E N C E S}

Abelson, R.D., 2006. Space missions and applications. In: Rowe, D.M. (Ed.), Thermoelectrics Handbook: Macro to Nano. CRC Press, Boca Ratón, pp. 56/1-56/29.

Antonova, E.E., Looman, D.C., 2005, Finite Elements for Thermoelectric Device Analysis in ANSYS, ICT 2005, pp. 215-218.

Cai, Y., Xiao, J., Zhao, W., Tang, X., Zhang, Q., 2011. A general model for the electric power and energy efficiency of a solar thermoelectric generator. J. Elec. Mat. 40 (5), $1238-1243$.

Gavela, D., Pérez-Aparicio, J.L., 1998, Peltier pellet analysis with a coupled, non-linear 3D finite element model, 4th Eur. Workshop on Thermoelectrics.

Ivanova, L.D., Petrova, L.I., Granatkina, Y.V., Zemskov, V.S., Sokolov, O.B., Skipidarov, S.Y., Duvankov, N.I., 2002. Extruded thermoelectric materials based on $\mathrm{Bi}_{2} \mathrm{Te}_{3}-\mathrm{Bi}_{2} \mathrm{Se}_{3}$ solid solutions. Inorg. Mater. 45 (2), 123-128.

Kajikawa, T., 2006. Thermoelectric power generation system recovering industrial waste heat. In: Rowe, D.M. (Ed.), Thermoelectrics Handbook: Macro to Nano. CRC Press, Boca Ratón, pp. 50/1-50/28.

Kuznetsov, V.L., Kuznetsova, L.A., Kaliazin, A.E., Rowe, D.M., 2002. High performance functionally graded and segmented $\mathrm{Bi}_{2} \mathrm{Te}_{3}$-based materials for thermoelectric power generation. J. Mater. Sci. 37 (14), 2893-2897.

Matsubara, K., Matsuura, M., 2006. A thermoelectric application to vehicles. In: Rowe, D.M. (Ed.), Thermoelectrics Handbook: Macro to Nano. CRC Press, Boca Ratón, pp. 52/1-52/11.

Pérez-Aparicio, J.L., Palma, R., Taylor, R.L., 2012. Finite element analysis and material sensitivity of Peltier thermoelectric cells coolers. Int. J. Heat Mass. Transfer 55 (4), 1363-1374.

Pérez-Aparicio, J.L., Taylor, R.L., Gavela, D., 2007. Finite element analysis of nonlinear fully coupled thermoelectric materials. Comput. Mech. 40 (1), 35-45.

Platzek, D., Karpinski, G., Drasar, C., Müller, E., 2005. Seebeck scanning microprobe for thermoelectric FGM. Mater. Sci. Forum 492-493, 587-592.

Semenyuk, V.A., 2006. Thermoelectric cooling of electro-optic components. In: Rowe, D.M. (Ed.), Thermoelectrics Handbook: Macro to Nano. CRC Press, Boca Ratón, pp. 58/1-58/21.

Virjoghe, E.O., Enescu, D., Ionel, M., Stan, M.F., 2010, Numerical simulation of thermoelectric system, 14th WSEAS Int. Conf. Systems (2), 630-635.

Yu, J., Zhao, H., 2007. A numerical model for thermoelectric generator with the parallel-plate heat exchanger. J. Power Sourc. 172 (1), 428-434. 